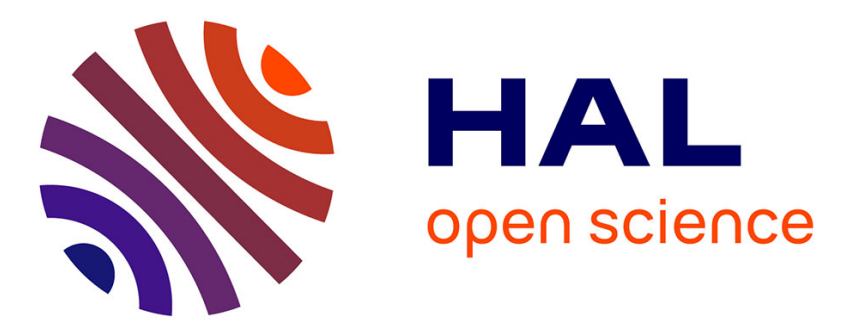

\title{
Nonlocal damage formulation with evolving internal length: the Eikonal nonlocal approach
}

\author{
G Rastiello, C Giry, F. Gatuingt, R. Desmorat
}

\section{To cite this version:}

G Rastiello, C Giry, F. Gatuingt, R. Desmorat. Nonlocal damage formulation with evolving internal length: the Eikonal nonlocal approach. Fifth International Conference on Computational Modeling of Fracture and Failure of Materials and Structures - CFRAC 2017, Jun 2017, Nantes, France. hal01623490

\section{HAL Id: hal-01623490 \\ https://hal.science/hal-01623490}

Submitted on 25 Oct 2017

HAL is a multi-disciplinary open access archive for the deposit and dissemination of scientific research documents, whether they are published or not. The documents may come from teaching and research institutions in France or abroad, or from public or private research centers.
L'archive ouverte pluridisciplinaire HAL, est destinée au dépôt et à la diffusion de documents scientifiques de niveau recherche, publiés ou non, émanant des établissements d'enseignement et de recherche français ou étrangers, des laboratoires publics ou privés. 


\title{
Nonlocal damage formulation with evolving internal length: the Eikonal nonlocal approach
}

\author{
G. Rastiello ${ }^{1}$, C. Giry ${ }^{2}$, F. Gatuingt ${ }^{2}$, R. Desmorat ${ }^{2}$ \\ ${ }^{1}$ CEA Saclay, DEN, DANS, DM2S, SEMT, Seismic Mechanics Laboratory, France \\ giuseppe.rastiello@cea.fr \\ ${ }^{2}$ LMT-Cachan/ENS-Cachan/CNRS/Université Paris Saclay \\ giry@1mt-cachan.fr, gatuingt@1mt-cachan.fr, desmorat@1mt-cachan.fr
}

Integral non-local (INL) formulations [1] are often used to regularize continuum damage models in the presence of strain softening laws. In numerical computations the introduction of an internal length allows for avoiding pathological mesh sensitivities. Some questions concerning the identification of the internal length, its possible evolution during damage process and the need for special treatments of non-locality operators near boundaries (e.g. edges, cracks) are however still open. A physical request is that material points separated by a crack or a highly damaged zone should not interact (despite what is done in standard non-local integral theories). This can be obtained by allowing non-local interactions to evolve depending on mechanical fields (e.g. damage [2], stress [3], etc.).

Different formulations where proposed in the literature for this purpose. In particular, based on the analogy between wave and information propagation within an elastic damaged medium, Desmorat et al. [4] proposed to reformulate the classic non-local averaging procedure in terms of the ratio of the time needed for an elastic wave to propagate between two material points and the corresponding time in undamaged conditions. Using such an approach in two- and three-dimensional contexts may however reveal complex. As no general analytical solutions for the wave propagation equation through the heterogeneous medium are available, time-consuming numerical solution procedures are indeed needed.

Based on the Wentzel-Kramers-Brillouin (WKB) approximation for high-frequency wave propagation in a damaged medium, the Eikonal non-local (ENL) formulation provides a novel interpretation of damage dependent non-local interactions both in isotropic and anisotropic contexts. From a mathematical point of view, interaction distances are now computed as the viscosity solution of a time-independent Eikonal equation with a damage dependent isotropic/anisotropic Riemannian metric. From a differential geometry viewpoint, this leads to consider that damage induces a curvature of the Riemannian space in which interaction distances are computed. Geodesic interaction distances determined in the curved space are used to compute non-local variables driving damage evolution, thus preserving the general theoretical framework of INL theories. This allows modeling non-local interactions that gradually vanish in damaged zones, leading to a progressive transition from diffuse damage to fracture.

In this contribution, the numerical properties of the ENL regularization technique are investigated. Non-local interactions in 2D damaged domains are illustrated by some ex- 
amples first. Attention is focused on "artificially" damaged domains, in order to put into evidence some key features of the Eikonal Non-Local formulation. A non-intrusive (or less intrusive as possible) numerical formulation [6] for modeling damage dependent nonlocal interactions within mechanical computations is presented then. It is obtained by coupling Fast-Marching [5] algorithms for computing interaction distances and a standard Finite Element (FE) procedure for solving the quasi-static equilibrium equations. Geodesic distances computed between Gauss points define the kernel of weighting function considered in integral non-local regularization method. Several numerical results of quasi-static simulations involving the failure of quasi-brittle materials in isotropic media are presented. This allows for showing the capabilities of the ENL formulation in properly modeling a progressive transition from damage to fracture (i.e., strain localization) and the regularization capabilities of the proposed approach. The problem of how adapt/enhance the numerical ENL framework for properly treating nonlocal interactions near free-boundaries is addressed then. Finally, a method for estimating discrete quantities (i.e. cracking) from continuous field is exposed. This technic, based on the post-treatment of the strain field, allows to investigate the capacity of ENL formulation to describe the strain localization at failure.

It should be noted that, although the method is illustrated with a simple isotropic damage model, the formulation proposed is however general. The extension to anisotropic contexts is also possible without major modifications. In this latter case, the only difference will concern the use of a Fast-Marching algorithm that now should be capable of dealing with anisotropic Riemannian metric fields.

\section{References}

[1] Bazant, Z.P., Jiràsek, M. Nonlocal Integral Formulations of Plasticity and Damage: Survey of Progress, 2002. J. Eng. Mech., 128(11), 1119-1149.

[2] Pijaudier-Cabot, G., Haidar, K. and Dubé, J.-F., 2004. Non-local damage model with evolving internal length. Int. J. Numer. Anal. Meth. Geomech. 28, 633-652.

[3] Giry, C., Dufour, F., Mazars, J., 2011. Stress based nonlocal damage model, Int. J. Sol. Struct. 48, 3431- 3443.

[4] Desmorat, R., Gatuingt, F., Jiràsek, M., 2015. Nonlocal models with damagedependent interactions moti- vated by internal time. Eng. Fract. Mech.. 142, 255-275.

[5] Sethian, J.A., 1996 A fast marching level set method for monotonically advancing fronts. Proceedings of the National Academy of Sciences of the United States of America. 93(4),1591-1595

[6] Rastiello, G., Giry, C. Gatuingt, F. Desmorat, R., 2017. Strain localization from a Eikonal Non-Local (ENL) Continuum Damage model with evolving internal length. To be submitted. 